\title{
JUST CARING: Do THE INDOLENT, THE INEBRIATED AND THE IRRESPONSIBLE DESERVE EQUAL ACCESS TO NEEDED HEALTh CARE?
}

Leonard M. Fleck ${ }^{*}$

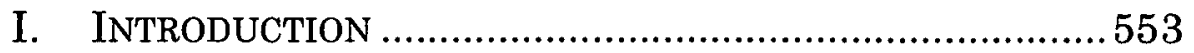

II. THE UNBEARABLE ARBITRARINESS OF JUDGMENTS OF Personal Responsibility in HEalth Care ................558

III. Political Liberalism, VAlue PluRalism, AND PERSONAL RESPONSIBILITY FOR HEALTH

IV. Physician Integrity and Personal Responsibility FOR HEALTH

V. PERSONAL RESPONSIBILITY FOR HEALth AND HEALTH CARE JUSTICE

\section{INTRODUCTION}

In 2012 we in the United States spent about $\$ 2.8$ trillion on health care, or about $17.8 \%$ of our Gross Domestic Product ("GDP"). ${ }^{1}$ That can be compared to 1960 when we spent only $\$ 27$ billion on health care (5.0\% of GDP) and to projections for 2022 of $\$ 5.0$ trillion (20\% of expected GDP). ${ }^{2}$ Most of that represents spending on the private side of the economy. ${ }^{3}$ More troubling, politically speaking, are

- Professor of Philosophy and Medical Ethics, Center for Ethics and Humanities in Life Sciences, College of Human Medicine, Michigan State University; Ph.D., St. Louis University.

1 Gigi Cuckler et. al., National Health Expenditure Projections, 2012-22: Slow Growth Until Coverage Expands and Economy Improves, 32 HEALTH AFF. 1820, 1820, 1829 (2013).

2 Id. For the 1960 figures, as well as a number of intervening years, see NATIONAL HEALTH EXPENDITURES; AGgRegate AND PER Capita Amounts, annual Percent Change and Percent DisTRIBUTION: SELECTED CALENDAR YeARS 1960-2012, http://www.cms.gov/Research-Statistics-Data-and-Systems/StatisticsTrends-and-Reports/NationalHealthExpendData/downloads/tables.pdf, archived at http://perma.cc/4E9E-SPAE.

$3 \quad$ Id. at 1829. 
Medicare and Medicaid cost projections. Medicare spending in 2012 was about $\$ 580$ billion, with projections to 2022 of $\$ 1.12$ trillion, and ten-year projections (2013-2022) of $\$ 8.5$ trillion. ${ }^{4}$ Medicaid spending in 2012 was $\$ 417$ billion, with projections to 2022 of $\$ 839$ billion, and ten-year projections $(2013-2022)$ of $\$ 6.35$ trillion. $^{5}$ Given these statistics, it is easily understandable why taxpayers and insurance premium payers are demanding that somebody do something to control escalating health care costs.

While there are multiple reasons why health care costs have increased much faster than the core rate of inflation in the economy, most health policy analysts would see emerging medical technologies as the primary driver of these cost increases. ${ }^{6}$ What this suggests is that someone ought to do something to control the cost and utilization of these emerging medical technologies. However, this proposal will quickly elicit public outrage about health care rationing. ${ }^{7}$ That outrage might be expressed this way:

$4 \quad$ Id. at 1827.

$5 \quad I d$.

6 Daniel Callahan deserves credit for early on identifying the connection between emerging medical technologies and what we would regard as health care "needs" (in the morally valenced sense of that term). His point is that there is no need for bypass surgery until bypass surgery has been invented. The same is true for every other advance in medicine over the past forty years. If medical progress were limitless, then the expansion of medical need and the costs of meeting those needs would be limitless as well. Callahan writes, "More fundamentally, however, it is medical progress itself that has rendered the enterprise of defining individual curative need as impossible, and thus with it notions of finding some identifiable baseline of healthcare to be provided to all." Daniel Callahan, What Kind of LifE: THE LiMits of Medical Progress 47 (1990); see also DANIEL CALLAHAN, TAMING THE BELOVED Beast: How Medical TeChNology Costs are Destroying OUR HEALTH CARE SYSTEM chs. 2-3 (2009).

7 The National Health Service ("NHS") in the United Kingdom relies upon the National Institute for Clinical Excellence ("NICE") to judge whether or not novel pharmaceuticals, such as trastuzumab for breast cancer, are truly cost-effective, i.e., yield enough medical good at a reasonable enough cost that they ought to covered by the NHS for all patients in the relevant clinical circumstances. NICE did approve trastuzumab as a first-line cancer treatment for non-metastatic breast cancer but denied funding once cancer has become metastatic. This elicited public outcries of "rationing" as the following article 
"How can a just or compassionate society deny lifeprolonging cancer drugs or an artificial heart to desperate patients simply because of the cost of these interventions?" Nevertheless, these same outraged citizens want more effective control of health care costs.

At this point another set of statistics is called forth. About $35 \%$ of cancers are avoidable through behavioral change. Most of the cancers alluded to in that statistic are related to smoking. ${ }^{8}$ Another statistic is that $94 \%$ of diabetes is avoidable through behavioral change. ${ }^{9}$ This is related to various unhealthy dietary choices, many of which are linked to what is referred to as the "obesity epidemic." That, in turn, is linked to a substantial portion of heart disease. ${ }^{10}$ For many individuals these statistics will suggest a cost-saving alternative to indiscriminate rationing. Namely, it is more to ration more selectively. Specifically, these individuals will contend that individuals whose compromised health is related to "irresponsible" health choices ought to be denied needed care, at least at social

demonstrates. Rebecca Smith, Breast Cancer Sufferers Denied Two Drugs on NHS, TELEGRAPH (Feb. 14, 2012, 7:00 AM), http://www.telegraph.co.uk/health/healthnews/9079213/Breast-cancersufferers-denied-two-drugs-on-NHS.html, archived at http://perma.cc/6D7A-BW7Z.

8 See Ahmedin Jemal et. al., Global Cancer Statistics, $61 \mathrm{CA}$ : CANCER J. CLINICIANS 69 (2011), available at http://onlinelibrary.wiley.com/doi/10.3322/caac.20107/pdf, archived at http://perma.cc/QT74-RSW6.

9 See Diabetes Statistics: Data from the 2011 National Diabetes Fact Sheet, AM. DIABETES ASs'N, http://www.diabetes.org/diabetesbasics/statistics (last updated Feb. 12, 2014), archived at http://perma.cc/RV4F-76HF. At present about 26 million Americans have diabetes, and another seventy-nine million are pre-diabetic. $I d$.

10 See generally James R. Hebert et. al., Scientific Decision Making, Policy Decisions, and the Obesity Pandemic, 88 MAYo CLINIC PROC. 593 (2013) ("Rising and epidemic rates of obesity in many parts of the world are leading to increased suffering and economic stress from diverting health care resources to treating a variety of serious, but preventable, chronic diseases etiologically linked to obesity, particularly type 2 diabetes mellitus and cardiovascular diseases. Despite decades of research into the causes of the obesity pandemic, we seem to be no nearer to a solution now than when the rise in body weights was first chronicled decades ago."). 
expense, or else ought to pay more for their health care, either in the form of higher insurance premiums or substantial co-pays and deductibles for those interventions related to health needs linked to "irresponsible" health behavior. ${ }^{11}$

Critics of "irresponsible" health behavior will sometimes make the moral argument that it is unfair that individuals who have taken very good care of their health, i.e., been responsible, should have to pay for the excessive health needs of those who have been irresponsible with their health. An analogy often invoked in this regard is automobile insurance. ${ }^{12}$ Drivers who have been very responsible in their driving habits, i.e., no accidents and very few moving citations, typically pay a lot less for their automobile insurance compared to irresponsible drivers who have been involved in multiple accidents or are frequently cited for traffic violations. If we see such discounts as fair and reasonable, the argument goes, we ought to see as equally fair and reasonable expecting those with greater health needs due to "irresponsible" health choices to pay more for their health care or else be denied that care. Further, it is morally troubling (for political liberals, not

11 I have placed the word 'irresponsible' in scare quotes because, as I will argue, it is used much too promiscuously and arbitrarily in ethical and policy discussions of personal responsibility for health to achieve rhetorical advantage. In an earlier essay I, and two of my colleagues, critically examined the use of the language of "irresponsibility" in connection with choices made by parents to avoid using alternate reproductive options for purposes of preventing the birth of a child with a serious genetic disorder. See Judith Andre et al., On Being Genetically "Irresponsible", 10 KENNEDY INST. ETHICS J. 129 (2000).

12 The CEO of the Safeway food store chain is one prominent proponent of this view with regard to personal responsibility for health. He wrote in a Wall Street Journal opinion piece: "As much as we would like to take credit for being a health-care innovator, Safeway has done nothing more than borrow from the well-tested automobile insurance model. For decades, driving behavior has been correlated with accident risk and has therefore translated into premium differences among drivers. Stated somewhat differently, the auto-insurance industry has long recognized the role of personal responsibility." Steven A. Burd, How Safeway is Cutting Health-Care Costs, WALL ST. J. (June 12, 2009, 12:01 AM), http://online.wsj.com/news/articles/SB124476804026308603, archived at http://perma.cc/S7MB-W5VS. 
just political conservatives) that individuals with very costly health care needs related to diseases over which they could have no control whatsoever, such as cystic fibrosis or Duchenne's muscular dystrophy or schizophrenia, should be denied affordable health insurance, and, hence, secure access to needed and effective health care, while those whose medical problems are related to "irresponsible" health choices should have all their health care costs covered because they happen to work for large employers with generous health benefits or else have Medicare or Medicaid coverage. ${ }^{13}$

No doubt the argument above has considerable persuasive power. However, I will argue that it is profoundly flawed, morally and politically speaking, and that its persuasive power should be resisted. More specifically, in this essay I will defend four major claims aimed at undermining the persuasive appeal of the argument above. First, it is harder to make fair, reasonable, non-arbitrary judgments of personal responsibility for health than most people realize. Second, if an insurer or some legislative body sought to introduce some sort of scheme for assessing personal responsibility for diminished health status (and needed medical therapy), such a scheme would almost certainly violate fundamental moral and political values, especially in a society that sees itself as being politically liberal. Third, if such a responsibility-for-health scheme were to be put into practice, the "judges" in such a scheme would likely have to

13 The view expressed in the last two sentences represents a common view among philosophers known as "luck egalitarians." They make a distinction between "brute luck" and "option luck." They defend an egalitarian view with regard to the fair distribution of health care resources for all those whose health care needs are a product of "brute luck," events over which an individual had no control. But they would limit the just claims to needed health care for those whose health needs are a product of "option luck," choices those individuals made that resulted in adverse health consequences for themselves. Such individuals, according to luck egalitarians, are justly given lower priority for meeting their self-caused health needs so long as social resources for meeting health needs are relatively scarce. See generally SHLOMI SEGALL, HEALTH, LUCK, AND JUSTICE (2009). 
be physicians whose professional integrity as physicians would be significantly compromised since they would be functioning more like prosecutorial assistants than patient advocates. Fourth, if the primary goal of this responsibilityfor-health scheme is to control health care costs and to do that more justly, then the likelihood in practice will be a more unjust state of affairs. Or, to put this last point more positively, there are numerous other ways of controlling health care costs justly that do not threaten the just claims to needed health care of those whose health needs may be self-caused in whole or in part.

If we had to summarize in a few sentences the key questions we would hope to answer fairly in this essay, it would be these: What may a just, liberal, egalitarian society do by way of tolerating, discouraging, regulating, forbidding, or punishing personal health choices that impose costs on others? Or, asked in a slightly different way, is it unjust to deny individuals whose health care needs are products of "irresponsible" behavioral choices equal access to the health care that they need? Is it unjust to deny a heart transplant to a smoker or obese individual simply because their heart disease is believed to be a product of their smoking or poor dietary habits? Is it unjust to charge smokers or obese individuals very high co-pays for health care interventions related to their smoking or poor dietary habits while excusing other individuals with comparable health problems from such co-pays because those other individuals were believed not to be responsible for their health care needs? My basic answer to all these questions is that those accused of being "irresponsible" with regard to maintenance of their health still have a just claim to equal access to needed health care, except in some rare circumstances.

\section{The UNBEARABLE ARBITRARINESS OF JUdGMENTS OF PERSONAL RESPONSIBILITY IN HEALTH CARE}

We start by considering a story intended to illustrate the difficulty of attributing personal responsibility for poor health status in a non-arbitrary way. Bishop and Brodkey 
tell us the story of Mary Jones, a fifty-three year old patient with diabetes and obesity. ${ }^{14}$ Some readers might wish to stop the story there. This is all they need to know to find Mary Jones guilty of personal irresponsibility for her medical condition. However, these conditions developed after she began to take an atypical antipsychotic drug for her schizophrenia. She is a poor resident of West Virginia. Her medical bills are covered by Medicaid. In order to remain eligible for "full" Medicaid coverage (now redescribed in West Virginia law as "enhanced" Medicaid coverage) she had to sign a treatment contract with Medicaid stating that she will keep all her medical appointments, attend diabetes education classes, and lose weight. She did in fact attend one class but became paranoid and left halfway through the class. She has gained five pounds. She has been given educational materials but she does not understand them. She missed her last appointment because she did not have bus fare. Her physician is now supposed to report her to Medicaid with the consequence that she could lose her mental health benefits.

A frequently cited statistic in the medical literature is that roughly $50 \%$ of patients are non-compliant with the recommendations of their physicians. ${ }^{15}$ It is easy to

14 See Gene Bishop \& Amy Brodkey, Personal Responsibility and Physician Responsibility--West Virginia's Medicaid Plan, 355 NEW ENG. J. MED. 756 (2006). The West Virginia Medicaid plan has been strongly criticized, in part because it is essentially a "punishment" approach to improving personal responsibility for health, in part because the focus of the plan is the poorest and most vulnerable portion of the population. The American College of Physicians has addressed this issue. In a position paper they articulate as their Position 2, "Incentives to promote behavior change should be designed to allocate health care resources fairly without discriminating against a class or category of people." See generally SHERYL MITNICK ET AL., AM. COLL. OF PHYSICIANS, ETHICAL CONSIDERATIONS FOR THE USE OF PATIENT InCENTIVES TO PROMOTE PERSONAL RESPONSIBILITY FOR HEALTH: WEST VIRGINIA MEDICAID AND BEYOND (2010), available at http://www.acponline.org/running_practice/ethics/issues/policy/persona 1_incentives.pdf, archived at http://perma.cc/LH88-H44P.

15 Marie Brown \& Jennifer Bussell, Medication Adherence: WHO Cares, 86 MAYo ClINIC Proc. 304, 304 (2011), available at 
interpret this statistic to mean that half the patients in the health care system are irresponsible with their health. That is, they are being given professional advice by someone who is committed to serving their best health interests. Instead of following that advice, having their health restored, and saving the health care system unnecessary health costs related to their non-compliance, they choose to disregard that expert advice and accept ongoing ill health that is likely to generate future health care costs that others in the health care system will have to bear. Certainly, Mary Jones would be described as one of these non-compliant patients. This is a true factual description. But the normative moral judgment is what really matters. Is it fair to conclude that Mary Jones has behaved irresponsibly and is deserving of being denied various mental health benefits because she has behaved irresponsibly?

Here are some critical questions that might be useful in providing a more dispassionate response to our last question. Why is Mary Jones obese and diabetic? She was given an atypical antipsychotic drug for her schizophrenia that had these side effects. She certainly cannot be responsible for her schizophrenia. Should she have informed her physician in a timelier manner of these evolving conditions so that she could be switched to a different medication? That sounds like it was her responsibility to do that. But what if her physician was a bit rushed when he gave her the prescription and was

http://www.ncbi.nlm.nih.gov/pmc/articles/PMC3068890/pdf/mayoclinpro c_86_4_007.pdf, archived at http://perma.cc/LY6L-AL7L. They write, "The treatment of chronic illnesses commonly includes the long-term use of pharmacotherapy. Although these medications are effective in combating disease, their full benefits are often not realized because approximately $50 \%$ of patients do not take their medications as prescribed. Factors contributing to poor medication adherence are myriad and include those that are related to patients (eg, suboptimal health literacy and lack of involvement in the treatment decisionmaking process), those that are related to physicians (eg, prescription of complex drug regimens, communication barriers, ineffective communication of information about adverse effects, and provision of care by multiple physicians), and those that are related to health care systems (eg, office visit time limitations, limited access to care, and lack of health information technology)."). 
insufficiently attentive in making sure she understood the potential side effects of this drug? That would seem to diminish her responsibility for these consequences. What if these side effects were more uncommon? Or what if these side effects were a result of idiosyncratic features of Mary Jones' genotype? What if these side effects were well known and Mary's physician emphasized strongly that she would need to limit her daily caloric intake to less than fifteen hundred calories to forestall those side effects? Mary failed in that effort because it would take something close to heroic will power to achieve that level of self-denial. How should we judge her responsibility for obesity and diabetes under those circumstances?

What if there was another antipsychotic drug that she could have been given that would not have these side effects for her, except that this was a much more expensive drug excluded from the Medicaid formulary? That would seem to diminish responsibility for her diabetes and obesity. What if from earlier on in life she acquired some problematic dietary habits in the way many adolescents do, a little too much starch and sugar in her diet, not enough to yield diabetes and obesity by themselves, but in combination with this prescribed drug would yield this outcome. Here it might be harder to disentangle factors for whose results one might be held responsible from factors for which one could not justifiably be held responsible.

Mary attended one of the classes she was required to attend but she became paranoid and left. We would not ordinarily hold individuals responsible for failing to control those paranoid thoughts. She was given educational material she could not understand. Perhaps she should have taken responsibility and asked a friend to help her understand the material. Perhaps her mental disabilities interfered with her ability to make very many friends. Perhaps the material itself should have been presented more simply. She missed an appointment because she did not have bus fare. Perhaps she should have taken responsibility for setting aside bus fare money at the beginning of the month that could not be used for any other purpose. This is an easy step to take for anyone who is 
securely in the middle class. Can we justifiably believe that it ought to be just as easy for Mary?

The conclusion I want to draw from this series of critical questions is that it is much more difficult to make some sort of clearly justified global judgment of personal responsibility for health regarding Mary Jones and whether or not she ought to be denied her mental health benefits by the West Virginia Medicaid program. My critic might wish to assert that this case is much too idiosyncratic, that it has nothing to do with the very large ethical and policy question of whether ordinary individuals who are not disabled by some severe mental disorder can be held responsible for unjustly imposing health care costs on others through engaging in some range of behaviors that have bad health consequences and high health costs. The usual litany of behaviors would include excessive alcohol consumption, the use of illegal recreational drugs, smoking, dietary habits that increase the risk of heart disease and diabetes, and various sorts of risky sexual behavior. All of these behaviors have been characterized in various religious contexts as being "sinful." But we will pass over that issue for now. Instead, we want to examine the very complex causal schemas that are typically associated with "irresponsible" health behaviors that result in serious and costly illness. ${ }^{16}$

16 Philosophers have argued for centuries about free will and determinism. That is a metaphysical debate. I am putting that debate entirely aside for purposes of this essay. My focus is on social practices and social judgments associated with attributing moral or legal responsibility for specific individual behaviors and their consequences. We are often capable of making such judgments well and correctly. For example, if an individual driver has struck and killed a pedestrian walking on the side of a country road, and if that driver had a blood alcohol level of .3 (roughly three times the legal limit), that driver will justifiably be charged with responsibility for that death. That he had a fight with his girlfriend earlier in the day or that his parents were alcoholics will be entirely irrelevant to making that judgment of moral and legal responsibility. But we argue below that it is much more difficult to make such judgments non-arbitrarily when we are supposed to assess responsibility for health outcomes (chronic disease states) that stretch back for decades and that are essentially multifactorial in their origin and evolution. 
It is morally significant that smoking a cigarette or becoming drunk at one holiday party will not result in either lung cancer or cirrhosis of the liver. These health problems have extraordinarily long and complex causal histories, only a portion of which involve what might be described as responsible behavioral choices by individuals. Consider the story of Michael. He started drinking at age twelve because this was a cool thing to do with his friends. This behavior continued into college where he was subjected to disciplinary action for several fights and property destruction related to his excessive consumption of alcohol. As he was about to enter law school he reflected on his behavior and decided that his drinking would have to moderate considerably. His father was an alcoholic whose "drinking problem" was tolerated by his mother. Both his parents tolerated Michael's drinking as well. One might ask at this point whether Michael's parents were irresponsible in failing to confront his drinking problem. Michael's law career went well for a number of years, but then his firm suffered some serious financial reversals and his marriage fell apart. He again started drinking heavily for several years before some friends were able to steer him into Alcoholics Anonymous. Over the past twenty-five years he has had periods of excessive drinking and sobriety that have each lasted several years. He has now been diagnosed at age sixty-three with cirrhosis of the liver. He has been clean and sober for the past five years. Three years ago he volunteered for a genetics research project looking at family history related to alcoholism (or other forms of substance abuse) and individual genotype. That research showed a strong linkage between specific features of his genotype and a vulnerability to alcoholism and other forms of substance abuse. ${ }^{17}$ The research was well done but it has also had its critics.

17 See Mary Jeanne Kreek et al., Genetic Influences on Impulsivity, Risk Taking, Stress Responsivity and Vulnerability to Drug Abuse and Addiction, 8 NATURE NEUROSCIENCE 1450 (2005); see also Richard Spanagel et al., A Systems Medicine Research Approach for Studying Alcohol Addiction, 18 ADDICTION BIOLOGY 883 (2013). 
How should we assess Michael's responsibility for his liver cirrhosis in connection with access to the health care that he needs right now? Would it be unjust if he were simply excluded from the liver transplant list because there are not enough livers for everyone with end-stage liver disease, and his disease was likely related to his excessive consumption of alcohol, as opposed to a disease process for which an individual had no responsibility at all? Or would it be unjust if he were expected to pay from his own pocket half the $\$ 300,000$ cost of a liver transplant, unlike everyone else with health insurance for whom virtually the entire cost would be covered by insurance? Does it matter that Michael has a net worth of less than $\$ 50,000$ ? Would it be unjust if Michael, and Michael-like liver transplant candidates, were given very low priority status on the transplant list, such that it would rarely be the case that anyone that far down the list would actually receive a transplant?

The point of these questions is that Michael would be condemned to a premature death if these questions are answered in the negative. This is reasonably characterized as a severe punishment for his irresponsible health behavior. And it is equally reasonable to characterize such a consequence as punishment, as opposed to regarding this consequence as the outcome of an alternate distributional criterion aimed at achieving a fairer allocation of health care resources. Defenders of the use of such severe consequences have contended that these are merely incentives aimed at shaping behavior for the benefit of the individual as well as the good of society. But John Harris has noted that if end-stage lung cancer or cirrhosis of the liver is not sufficient to alter the smoking or drinking behavior of individuals, then any additional "incentives" are unlikely to make a difference either. ${ }^{18}$ He concludes that the most apt characterization of the severe limiting of access to needed health care for those whose ill health is

18 John Harris, Could We Hold People Responsible for Their Own Adverse Health? 12 J. CONTEMP. HEALTH L. \& POL'Y 147 (1995). 
attributed to personal choices is that they are being punished. 19

If, however, individuals are going to be punished for their "irresponsible" health behaviors, should they not have some formal opportunity to defend themselves against what must be described as "charges"? At the very least, should not physicians be expected to issue a health care version of a Miranda warning: "Anything you say regarding your bad health behavior can and will be used against you by Medicaid, Medicare, or your managed care plan." This would certainly have an adverse impact on the doctorpatient relationship. Ordinarily patients expect their physicians to be their advocates for good health and the healing of their present infirmities. In order to achieve those desired therapeutic outcomes patients reveal very intimate details of their lives and health-related behavior, some of which may be deeply shameful to them. They do this because they believe this information will be held in confidence (with only a few well-known exceptions) by their physician. If instead physicians inquire diligently about the frequency and magnitude of bad health behaviors so that they can provide more comprehensive indictable information to the patient's insurer or employer, then the physician is really acting more like a prosecutor (albeit a kindly prosecutor aiming to build trust). If our health care system were to evolve in a direction such as this, it would be reasonable to insist that physicians clearly identify themselves either as prosecutorial physicians or as defense physicians so that patients would know to whom they were speaking and what the consequences might be of whatever they might reveal.

Someone might object that this discussion of punishment is entirely misleading. However, the premise behind this essay is that the need for health care rationing is inescapable, that we cannot afford as a society to meet all

19 Id. ("If it is correct that refusals to treat or low positions on waiting lists are unlikely to have much impact on behavior, then discrimination against smokers in the allocation of health care resources will effectively function as punishment and should be seen as such."). 
the health care needs that we are technically capable of meeting, and, consequently, we need some criteria for determining fairly which health care needs may be given low priority and left unmet. The proposal of some in our society is that individuals whose health needs are a product of self-caused unhealthy choices should have their access to needed health care diminished, directly or indirectly, because they have otherwise imposed an unfair burden on others in our society who will be expected to pay the costs of those unhealthy choices through higher insurance premiums. In being denied what they otherwise would have a just claim to, these individuals are being punished.

At this point two critical comments are in order. First, we need to ask again why some individuals are being punished. The short answer is they have made "irresponsible" choices that have resulted in harm to their health and costs that are unfairly imposed upon others in society. This seems like a perfectly general charge. In practice, however, as noted already, the "irresponsible" choices for which individuals are being punished are very limited in number, namely, abuse of alcohol, smoking, drug abuse, bad dietary habits, and assorted sexual "sins." But numerous other kinds of behavior, albeit socially respectable behavior, frequently enough result in harmful consequences to self, but no one is out crusading to have those individuals punished for imposing costs unfairly on the rest of society. Women who wear high heels as a fashion statement and injure their ankles would be one example. Another example would be avid recreational runners who bang up their knees from running long distances on a daily basis for years and cost someone like myself, a sedate walker, higher taxes and insurance premiums. We could also mention participants in extreme sports, or well-compensated executives who lead very stressful lives, or individuals working in occupations with high levels of accidents and injuries, or couples who choose to have children (imposing costs on the childless). What if a sixty-five-year-old patient has total cholesterol of 210 and is informed by his physician that he has a $14 \%$ chance of a heart attack or stroke over the next ten years unless he 
takes a statin, which would reduce that risk by half? $\mathrm{He}$ declines the statin because of the side effect of muscle weakness. Six years later he suffers a moderate heart attack.

All of these examples involve choices that individuals have made voluntarily, knowing that there were health risks that would result in a portion of those costs being imposed upon others who had not made such choices themselves. Yet none of these individuals are subjected to social criticism for being "irresponsible," nor are they subjected to punishment in the form of less equal access to the health care they would need for having undertaken those risks. This would suggest that there was something arbitrary and unfair about singling out for punishment (unequal access to needed health care) only a very limited range of behaviors associated with lifestyle choices. Likewise, it is difficult to reconcile such an arbitrary and coercive approach to encouraging personal responsibility for health with the fundamental principles of a liberal society.

Our second criticism related to punishing individuals for self-inflicted health needs is an epistemic point. If individuals are going to be subjected to punishment for "irresponsible" health choices, then there ought to be a high degree of confidence that those judgments of "irresponsibility" have themselves been made responsibly, thoughtfully, and on the basis of a fair weighing of the relevant evidence. Recall our patient with the elevated cholesterol who has declined a statin. That heart attack might still have happened, whether or not he was taking a statin. Given the current arguments among medical researchers regarding who should be on statins and how effective they are, should we judge this patient to have acted "irresponsibly" regarding his health? What exactly would be the "medical evidence" that would support or refute such a judgment?20

20 Something of a medical firestorm was set off with the publication of a two new reports regarding the number of people who ought to be on statins to reduce their risk of stroke or heart disease. The most controversial elements of these reports involved a new risk calculator for determining which patients were at elevated risk for 
Consider again the stories of either Mary Jones or Michael. No doubt both individuals made numerous voluntary choices that each contributed in a small way to their serious health problems. But it is also true that there were numerous non-voluntary causal factors that also contributed to their serious health problems. Furthermore, there were other individuals in their lives (Mary's physician or Michael's parents) who made choices that "might" be characterized as being somewhat irresponsible, given their social roles and responsibilities. Those choices too contributed to some degree to the serious health problems with which they are now afflicted. Norman Daniels also calls attention to failures of social responsibility with regard to health, which he sees as more fundamental and morally problematic than failures at the individual level. ${ }^{21} \mathrm{He}$ notes, for example, that our federal government has

stroke or heart disease. If that risk calculator were introduced into clinical practice today, about thirty-three million more Americans would be told they needed to be on statins. See David C. Goff et al., 2013 ACC/AHA Guideline on the Assessment of Cardiovascular Risk: A Report of the American College of Cardiology/American Heart Association Task Force on Practice Guidelines, Circulation (Nov. 12, 2013), http://circ.ahajournals.org/content/early/2013/11/11/ 01.cir.0000437741.48606.98.full.pdf, archived at http://perma.cc/B7RRRA25; see also Neil J. Stone et al., 2013 ACA/AHA Guideline on the Treatment of Blood Cholesterol to Reduce Atherosclerotic Cardiovascular Risk in Adults: A Report of the American College of Cardiology/ American Heart Association Task Force on Practice Guidelines, CIRCULATION (Nov. 12, 2013), http://circ.ahajournals.org/ content/early/2013/11/11/01.cir.0000437738.63853.7a.full.pdf, archived at http://perma.cc/6FYM-CN4E. These reports were critically assessed by Paul Ridker and Nancy Cook, Statins: New American Guidelines for Prevention of Cardiovascular Disease, 382 LANCET 1680 (2013); see also John Ioannidis, More Than a Billion People Taking Statins? Potential Implications of the New Cardiovascular Guidelines, 311 JAMA 463 (2013). The point of these citations is that when there is this intense controversy among medical experts regarding the interpretation and application of these clinical guidelines it seems especially unreasonable and unfair to judge patients as being "irresponsible" should they refuse statins and sometime later suffer a stroke or heart attack.

21 See generally Norman Daniels, Individual and Social Responsibility for Health, in RESPONSIBILITY AND DISTRIBUTIVE JUSTICE 266-86 (Carl Knight \& Zofia Stemplowska, eds., 2011). 
subsidized tobacco production and for a very long time did nothing to regulate cigarette advertising by corporations. ${ }^{22}$

The epistemic question (with moral consequences) is that of how we ought to correctly apportion these different factors in arriving at a global "responsibility" judgment that will result in either Michael or Mary being deprived of needed health care that could result in a premature death for one or both of them. How can we be reasonably certain that we have identified all the responsibility-relevant factors? What do we believe are the relevant norms for correctly assigning the right weight to each of the relevant factors that should contribute to that global "responsibility" judgment? It is not at all obvious that we have such agreed upon norms in our society that we can reasonably and fairly apply to either of our scenarios. Nor is it obvious that as a society we are willing to expend very substantial social resources to gather all the information needed for a fair and reasonable judgment in the millions of cases annually that would require such a judgment in the real world.

Finally, I would ask the reader to imagine Michael going through as many as ten cycles of relapse and sobriety of varying lengths over the course of his life. How would we imagine an omniscient divine being judging whether or to what degree Michael ought to be punished for his "irresponsible" health-destructive behavior? Should that divine being think of Michael as a persistent penitent (worthy of mercy and compassion) or as a pusillanimous sinner (worthy only of just condemnation)? At the risk of divine annoyance, my belief is that such an omniscient being would be genuinely stumped, especially if that divine being endorsed as reasonable the liberal pluralistic society in which Michael lived. If this is a reasonable thought experiment, then we non-divine and cognitively limited beings ought to be more responsible and restrained when we are tempted to make global judgments of "irresponsibility" for allegedly self-generated health needs and then punish individuals by denying them equal access to the health care that they need. 


\section{Political Liberalism, Value PluRalism, and PERSONAL RESPONSIBILITY FOR HEALTH}

We turn now to the question of whether giving legitimacy to policies aimed at punishing individuals for "irresponsible" health choices are compatible with the fundamental values that define what a liberal pluralistic society is. There are many varieties of political liberalism. John Rawls and Ronald Dworkin would represent two such well-known variants. ${ }^{23}$ What would seem to be common among these variants would be (1) a commitment to a reasonable value pluralism, (2) a commitment to state neutrality among competing philosophical and religious world views, and (3) respect for some range of equal individual rights. The commitment to value pluralism means that the multiple reasonable values that individuals might use to shape their lives will be equally worthy of respect in the eyes of the state. In other words, there are many ways for citizens in a liberal society to lead good lives that are compatible with the basic political framework of a liberal society. The state itself will not recognize any one value or set of values as superior to all other values, nor will the state establish any preferred hierarchy of values.

In general, a liberal society wants to grant individuals a very broad swath of political space in which they can work out for themselves what they judge to be a fulfilling life. The expectation is that individuals may not use their liberty rights to infringe upon the equal liberty rights of others, nor may individuals use their liberty to undermine common or public interests (clean air and water, for example) that the state has the right to protect for the benefit of all. Disagreements regarding public policies will be a necessary feature of a liberal pluralistic society, but those disagreements are to be resolved through mutually

23 John Rawls, POLITICAL LIBERALISM (1993); RONALD DWORKIN, Sovereign Virtue: The TheORY AND PRACTICE OF EQUALITY (2000). Though both Rawls and Dworkin are political liberals and egalitarians, Dworkin is committed to the version of egalitarianism known as luck egalitarianism. 
respectful political conversation and constitutionally legitimate political processes.

So far as personal responsibility for health is concerned, a liberal state may offer various opportunities for individuals to achieve a better understanding of how they might protect their own health. Such educational opportunities are just that-opportunities, which may be freely accepted or freely declined. Creating such opportunities is a legitimate public interest. Likewise, a liberal society may subsidize the cost of various forms of preventive health care as a way of encouraging individuals to take better care of their health. Again, this is an opportunity, not an obligation. ${ }^{24}$ A liberal society will also respect individuals who choose one dominant value for their lives, such as "maximizing good health." Such individuals might impose no "excess" or "unjust" health costs on others, which is admirable. But a liberal society cannot require

24 It must be noted that one other characteristic of liberal societies is a commitment to protecting "fair equality of opportunity." One way in which this is accomplished is by providing free public education through at least high school and heavily subsidized education beyond that. Norman Daniels has argued that access to needed health is just as important to protecting fair equality of opportunity as free public education. NoRman DANIELs, JUST HEALTH: MEETING HEALTH NEEDS FAIRLY (2008). For example, if individuals with serious chronic health care needs are denied access to the health care that would ameliorate those needs, perhaps because they are denied health insurance or could not afford health insurance, then those individuals will have great difficulty securing or holding even a menial job. Id. In that respect Daniels contends they are being treated unjustly. Id. They do not have fair access to the normal opportunity range of that society. And for this reason he concludes that health care should be thought of as something "morally special," that is, not just another consumer good to be distributed in accord with ability to pay. Id. at ch. 2. . If health care is indeed morally special, then there is something morally problematic (unjust) about punishing individuals by denying them access to needed health care because those health care needs were generated by "irresponsible" health choices. This is especially true, as argued in the prior section of this essay, if the "irresponsible" health-related behaviors are somewhat arbitrarily identified and if the causal factors that actually result in a bad health outcome are a complex mix of voluntary factors (the primary focus of attention), and non-voluntary and somewhat voluntary factors (mostly ignored by those who judge these behaviors). 
that all or any of its citizens adopt this value as a dominant value in their lives, or even as a very important value. The practical implication of this view is that individuals will take various degrees of risk with their health because there are other things they value more highly. Every time we drive our cars to get somewhere more quickly rather than less quickly we are putting ourselves and others at risk of an automobile accident that might be due to road and weather conditions or mechanical failure or a brief distraction or poor judgment by another driver or mental fatigue and so on. The consequence will often be injuries requiring medical attention, which means health care costs that others will have to bear "unjustly." That brings us back to our advocates for more personal responsibility in matters of health. They will argue that a liberal society is about rights and responsibilities. That is, we have no right to impose the costs of our "irresponsible" choices on others. But by the same token a liberal society must avoid legitimating what some have described as an "oppressive healthism." 25 Where then should a line be drawn?

One reasonable response might be that we should simply avoid drawing any such line because we cannot draw that line even in a roughly just way, except perhaps in a very limited range of circumstances. One example of such a circumstance would be the alcoholic who now needs a liver transplant because of his liver disease related to his alcoholism. Current practice is that such a transplant candidate must demonstrate sobriety for a period of at least six months before receiving that transplant. This practice is not intended as punishment for irresponsible alcohol use. Rather, the concern is that if an individual is so addicted to alcohol that they might go on a drinking binge over several days, they will then fail to take the anti-rejection medications that are absolutely necessary to prevent rejection of the transplanted liver. That liver would then have been wasted. That is, it would otherwise have been

25 See Stacy Carter et al., Shared Health Governance: The Potential Danger of Oppressive "Healthism", 11 AM. J. BIOETHICS 57 (2011). This essay is a critical response to an essay by Jennifer Ruger, Shared Health Governance, 11 AM. J. BIOETHICS 32 (2011). 
given to someone with a $50 \%$ chance of ten-year survival with that liver. Given the scarcity of this resource and given "fair warning" to individuals in these circumstances, such a practice is neither unreasonable nor unjust. ${ }^{26}$

Going back to the "irresponsible" health choices that many make and that result in health care costs "unjustly" imposed on others who do not engage in those same behaviors, what should be done to remedy that "injustice"? Perhaps we should be more critical and inquire whether there are true injustices that need to be remedied. The social fact seems to be that virtually everyone takes different risks with their health for different reasons at various times in their lives. A liberal pluralistic society permits and respects such differential choices. Some individuals may have "Type A" personalities (for whatever reasons, maybe genetics, maybe parental expectations) with the result that they have much more self-imposed stress in their lives with the likely health consequences of that stress. ${ }^{27}$ Other individuals may be avid skiers or mountain climbers with the risks those hobbies entail. Still other individuals may adopt more sedentary habits, such as stamp collecting, which may have adverse health consequences. Various dietary choices will have a range of potential health risks associated with them. Allowing children to play football or basketball will result in some number of harmful health outcomes. There is gardening in the summer sun or relaxing at the beach. This list can get enormously long if we think hard enough about it. Further, if we were committed to being proverbial "health saints" who made health maintenance the absolute highest value in our lives, relative to which all other life activities that carried any risk to health would be foregone, we would have

26 See Carl Cohen et al., Alcoholics and Liver Transplantation, 265 JAMA 1299 (1991).

27 We should not forget that such individuals will often be extraordinarily productive members of society. That is, society might benefit greatly from their "stressful" work habits, much more so than any costs their later health problems might impose upon society. Surely it would be awkward and inappropriate to accuse such individuals of being "irresponsible" and denying them equal access to the health care they needed for their "choice" of this stressful lifestyle. 
very dull lives. It is difficult to imagine anyone embracing this as an ideal "good life." Under these circumstances the reasonable understanding that we seem to collectively endorse is that we will use the insurance mechanism to effectively pay for our health-related inadequacies, faults, failings, errors, bad choices, and being a bit irresponsible. That is, we agree not to regard the health costs that we impose upon one another as being unjust. We will still chide or encourage one another to watch our weight, get more exercise, wear our seat belts, and so on. That too is encouraged in a liberal pluralistic society because it may achieve some social or personal good non-coercively. ${ }^{28}$

We have mentioned genetics several times already, mostly to suggest that an individual's genetic endowment might diminish to some degree that individual's responsibility for a bad health outcome linked to those genetic features. The obvious point is that individuals have no control over their genetic endowment. However, given our rapidly expanding genetic knowledge and related genetic capabilities, there is a different kind of healthrelated "irresponsibility" that also represents a threat to the values that define a liberal society. Children born with serious and costly genetic disorders represent a substantial health care cost that is imposed on "others" who are not the parents of such children. Clearly the children themselves are not at fault for their genetic endowment, and, if it were twenty years earlier, we would say the same of the parents. However, what we have today is the capacity to do Whole Genome Sequencing for less than $\$ 5000$ as well as preimplantation genetic diagnosis ("PGD"). ${ }^{29}$ The practical

28 For a critical assessment of using social policies to bring about greater personal responsibility for health, see Daniel Wikler, Persuasion and Coercion for Health: Ethical Issues in Government Efforts to Change Life-styles, 56 MILBANK MEMORIAL FUND. Q. 303 (1978). Likewise, Elizabeth Anderson is concerned, as a political liberal, that such government efforts would effectively erase the line between the public and the private to the detriment of individuals. Elizabeth Anderson, What is the Point of Equality? 109 ETHICS 287 (1999).

29 Carol Caddwalladr, What Happened When I Had My Genome Sequenced? GUARDIAN (June 8, 2013, 2:45 PM), 
implication of these medical advances is that future possible parents have a significant capacity to choose the genetic endowment of their future possible children. ${ }^{30}$

The obvious question that can be posed is: Are such future possible parents rightly judged to be "irresponsible" if they fail to avail themselves of these medical options in order to make a more responsible choice of a future possible child? Current predictions are that in the next year or two we will have the ability to do whole genome sequencing for $\$ 1000.31$ Could a liberal pluralistic society require that all marital partners intending to have children have such a test so that a couple could then know what significant genetic risks were possible for their future possible children so that they could make a more responsible choice regarding the genetic endowment of those children? Armed with such knowledge, a couple could then conceive using in vitro fertilization to produce a dozen or so embryos grown to the eight-cell stage when they would then be genetically analyzed, thereby allowing the couple to responsibly choose the "least flawed" embryo. The cost of PGD is about $\$ 40,000-60,000$ for a successful pregnancy. ${ }^{32}$ Would such a policy be any less illiberal if the federal government, as a way of showing social responsibility, paid for this testing? Further, would strong advocates for the right-to-life

http://www.theguardian.com/science/2013/jun/08/genome-sequenced, archived at http://perma.cc/KB6F-AJCZ.

30 See Leonard Fleck, Do Future Possible Children Have a Just Claim to a Sufficiently Healthy Genome? in MEDICINE AND SocIAL JUSTICE: ESSAYS ON THE DISTRIBUTION OF HEALTH CARE 446-57 (Rosamond Rhodes et al. eds., 2002).

31 See Ashlee Vance, Illumina's New Low-Cost Genome Machine will Change Health Care Forever. Bloomberg Business Week (Jan. 15, 2014). http://www.businessweek.com/articles/2014-01-15/illuminas-new ${ }^{-}$ low-cost-genome-machine-will-change-health-care-forever, archived at http://perma.cc/P7DG-AMYG.

${ }_{32}$ See Reproductive Health Technologies Project, Pre-implantation Genetic Diagnosis http://www.rhtp.org/fertility/pgd/ (last visited May 14, 2014), archived at http://perma.cc/Q3DV-7DAF. As noted in this article the cost for IVF is about $\$ 9,000$ per cycle and the cost for PGD will be $\$ 4,000-\$ 7,500$ per cycle. On average three cycles are needed for a successful pregnancy, which yields a likely cost of $\$ 40,000-\$ 60,000$ for a successful pregnancy. 
perspective have just cause to complain because their tax dollars would be used to underwrite the cost of a procedure that involved the disposal or destruction of numerous excess embryos? What seems clear is that these potential policies are clearly incongruent with respect for individual rights and other basic liberal commitments. But an unqualified emphasis on personal responsibility for health would have such potential consequences as a practical implication. ${ }^{33}$

\section{PHYSICIAN INTEGRITY AND PERSONAL RESPONSIBILITY FOR HEALTH}

If patients are going to be punished via some diminishing of health benefits to which they would otherwise be entitled because of "irresponsible" health choices that created some specific health needs, then someone will need to make the judgment that some current health need is linked to clearly "irresponsible" healthrelated behavior. The obvious candidate for such a role is a patient's physician. However, physicians are trained to be compassionate and nonjudgmental. This is what patients legitimately expect. Further, patients with serious illness are often anxious, vulnerable, and largely dependent upon medical expertise and advice. Physicians should not impose their personal values on patients. This is because (1)

33 A similar sort of example related to alleged parental "irresponsibility" can be brought up with regard to the obesity epidemic. Some medical research suggests that the fetal environment and maternal choices may result in a permanent altering of the endocrine-metabolic status of the fetus, thereby making the fetus more vulnerable to either diabetes or obesity later in life. Kanaka-Gantenbein concludes that "both intrauterine nutrient restriction as well as intrauterine excessive supply may predispose for the development of adult diabetes." Christina KanakaGantenbein, Fetal Origins of Adult Diabetes, 1205 ANNALs N.Y. ACAD. SCI. 99 (2010); see also Kristin Wartman, Bad Eating Habits Start in the Womb, N.Y. TIMES (Dec. 1, 2013), http://www.nytimes.com/2013/12/02/opinion/badeating-habits-start-in-the-womb.html?emc=eta1\&_r=0, archived at http://perma.cc/F7CZ-HLSS. Again, putting in place any policy that was aimed at "supervising" parental eating behavior in this context would be an incredibly intrusive violation of individual privacy rights that should not be judged as a fair or reasonable way of correcting these alleged instances of parental "irresponsibility." 
patients are fearful and vulnerable; (2) physicians are in a more powerful position because of their social authority and medical expertise; and (3) the authority that physicians have is granted to them by the state for a public purpose, not as an opportunity to recruit patients as supporters of their personal religious or ideological beliefs and values. No one doubts that physicians should legitimately advise and educate patients about their health problems. Physicians should encourage patients to quit smoking, watch their weight, exercise more, and so on. But physicians must refrain from coercing or manipulating patients to achieve health outcomes that competent patients do not autonomously embrace.

Physicians are clearly open to moral criticism if they coerce or manipulate patients into making choices that are more congruent with that physician's personal values. But this is equally true if physicians allow themselves as physicians in the doctor-patient relationship to be used to impose preferred social or political values not congruent with the core moral commitments of medicine. This is what seems to be happening in the West Virginia case of Mary Jones discussed earlier. That is, physicians are being used to gather "evidence" that will be used by a third party (the state or an insurance company) to punish patients for aberrant health behavior. In such a situation physicians are no longer trustworthy agents of their patients' health interests. Instead, they are acting as health police assisting someone functioning as a health prosecutor to identify and punish health criminals without the benefit of a trial or other due process protections. This would clearly alter for the worse the doctor-patient relationship. At the very least patients who were mindful of this conflict of interest would be motivated to lie or withhold therapeutically relevant information, potentially at risk to their own health.

Physicians are supposed to be nonjudgmental. But if physicians are expected to gather evidence for insurers of miscreant health behavior by their patients, then they are being quite judgmental. Further, there is ample opportunity in such circumstances for the most arbitrary and subjective of judgments. We can imagine that insurers 
might wish to "keep things simple" and focus on a few bad health behaviors, such as smoking, consuming fatty foods, alcohol and drug abuse, and promiscuous sexual behavior. As noted earlier, these are the sorts of behaviors that have a "sinful" caste to them. Physicians would be behaving in a distinctly illiberal way if the focus of their reporting "irresponsible" health outcomes were these behaviors. Beyond that, what physicians are doing for the third parties seeking this information is certifying that these patients have made "irresponsible" behavioral choices. As noted earlier, however, it would be very unlikely that most physicians would invest the time and effort needed to do a thorough assessment of the complex causal factors (genetic, social, environmental) stretching back several decades in the case of a Michael-like patient for purposes of judging fairly the degree to which a patient before them now was "responsible" for their current health need. In other words, such judgments would quite likely be very arbitrary and subjective, hardly a reasonable basis for determining whether someone did not have an equal just claim to needed health care.

Finally, physicians have very strong obligations to protect confidentiality, and patients have strong privacy rights. But neither is absolute. Tarasoff $v$. Regents of the University of California showed that health professionals have a "duty to warn" that trumps obligations of confidentiality when there is the risk of serious, imminent, and irreversible harm to self or others, and there is no alternative way of averting hat harm except by a breach of confidentiality. ${ }^{34}$ In that case a young man told his psychologist that he intended to kill his former girlfriend. It was apparently clear that this was a genuine intent, not simply an angry fantasy. Hence, the conditions for invoking the "duty to warn" were satisfied. But if that young man had, instead, expressed intent to defraud that young woman of $\$ 1000$, the conditions for invoking the "duty to warn" would not be satisfied. This would not be an irreversible harm, nor would it be serious enough to justify a breach of

34 See Tarasoff v. Regents of the University of California, $17 \mathrm{Cal}$. 3d 425, 440-41 (1976). 
confidentiality. Likewise, if a patient's bad health behavior imposes "unjust" health costs on others, this would not provide sufficient justification for a physician to breach confidentiality by revealing all manner of private information about a patient's personal health choices for purposes of helping the state or an insurance company punish that individual's "irresponsible" health behavior. Further, if the need to control health care costs is what has drawn attention to unhealthy personal behavior, then we are morally obligated to inquire whether there are alternative ways of controlling health care costs that do not have the moral costs associated with punitive efforts to reshape unhealthy personal behavior. We turn next to addressing the health care justice issues related to making judgments of personal responsibility for health.

\section{PERSONAL RESPONSIBILITY FOR HEALTH AND HEALTH CARE JUSTICE}

Earlier in this essay we argued that it was less than obvious that patients who were judged to have made "irresponsible" health choices had unjustly imposed health care costs on others. For the sake of argument we are going to put aside that claim. Instead, we will concede that individuals who have been less than fully responsible in caring for their health and who now have serious and costly health needs related to that less than responsible healthrelated behavior have added unnecessarily (and unjustly) to the problem of escalating care costs. Hence, if we need to do something to control escalating health care costs for society, then it is not unjust if society either forces these individuals to internalize those costs or else forego the health care that they otherwise need. This is not an unreasonable argument but $I$ will still argue that it is less than adequately persuasive.

Our health care system is riddled with injustices, at least as judged from a moderately egalitarian perspective. But it is not as if all injustices are equally unjust. Some injustices are worse than others. A good moral rule would be that greater injustices ought to be remedied before lesser 
injustices. What I want to argue in this concluding section is that there are more serious injustices in our health care system than the alleged injustices associated with "irresponsible" health-related behavior by individuals.

Space does not permit an entire treatise on competing theories of health care justice as applied to the problem of health care rationing and cost containment. My own view is that none of these competing theories of health care justice can address adequately the complex problems of health care justice within the American health care system. What we need instead is a pluralist account of health care justice. ${ }^{35}$ Put simply, such an account will require a careful balancing of considerations of liberty, equality, social utility, efficiency, and effectiveness. There is no algorithm that tells us how these different considerations should be balanced or weighted in relation to each other in specific rationing contexts. This will be a matter of what John Rawls refers to as wide reflective equilibrium and rational democratic deliberation, the latter being constrained by what I refer to metaphorically as "constitutional principles of health care justice." 36

The starting point for thinking about health care justice must be the claim that health care is "morally special." For the most part health care is not just another consumer good to be distributed in accord with an individual's ability to pay. It is appropriately a matter of justice. There are two important reasons for concluding that health care is a matter requiring just distribution. First, health care today is closely related to protecting "fair equality of opportunity." Individuals who are denied access to needed health care and suffer the functional deprivation linked to unmet health care needs will also be denied access to what Norman Daniels refers to as the "normal opportunity range" of a

35 I argue at length for this view in my book. See LEONARD FLECK, JUST CARING: HEALTH CARE RATIONING AND DEMOCRATIC DELIBERATION ch. 4 (2009).

36 Id. at ch. 5 (explaining in detail there what these constitutional principles of health care justice are, how they come to be articulated, how they are balanced in relation to one another, and what their role is is establishing "boundaries" for democratic deliberation and what may be regarded as a legitimate outcome of that deliberative process). 
society. ${ }^{37}$ Second, health care in the United States is properly thought of as largely a "public good," a product of enormous social investment in medical research, training highly skilled health professionals, and building health facilities. Virtually all in our society, whether insured or not, have paid through taxes for the creation of this system to which they ought to have fair access. This is essentially the basis for a moderate egalitarian perspective on health care justice.

A liberal moderate egalitarian is committed to the view that all in our society deserve equal concern and respect with regard to access to needed health care. Further, the relevant basis for determining how health care ought to be distributed justly is need, not social worth, not desert, not ability to pay. As noted earlier, however, health care needs are endless and social resources for meeting those needs are limited. Hence, we need to consider how to make rationing decisions fairly. The fundamental commitment of the liberal moderate egalitarian is that individuals in similar clinical circumstances with similar health care needs ought to receive equal access to that needed health care. If two individuals in their fifties have early stage colorectal cancer, and if the cancer is equally treatable for both individuals, but if only one individual has the ability to pay the $\$ 30,000$ cost of that treatment (which will allow him to live another twenty years), and if the other individual is denied that treatment for lack of ability to pay (which will result in his premature death four years later), then that latter individual has been treated unjustly from the perspective of a liberal moderate egalitarian.

Here is another scenario. If both these individuals above have Stage IV metastatic colorectal cancer, and if the only intervention that might prolong their lives an additional five months is a $\$ 100,000$ drug, such as bevacizumab, and if there is a rationing protocol that has been approved through a fair process of democratic deliberation that would deny anyone in these medical circumstances this drug because it yielded too little medical good at too high a price, and if both 
these individuals are denied this drug at social expense, then this is perfectly acceptable to a liberal moderate egalitarian. That is, neither has been treated unjustly. Both have been denied a bit of life prolongation. But the moral justification would be that the resources thereby saved could be redeployed to meet other higher priority health care needs as judged from a moderate egalitarian perspective. More specifically, those resources could be redeployed to meet the health care needs of our uninsured fifty-year old with a treatable early stage cancer that will result in a greater medical good (sixteen more years of life) at a much lower cost than for bevacizumab for a Stage IV cancer. ${ }^{38}$

Next imagine a scenario with George and Harry. Both are sixty years old; both are in Stage IV heart failure. Both have a predicted life expectancy of less than two years. George has had two heart attacks in the past three years. He has been reasonably attentive to his diet and weight all his life. He has a body mass index of twenty-six (only very slightly overweight). Harry has also had two heart attacks in the past three years, but he has a Body Mass Index of thirty-one (which identifies him as being obese). Harry has a life story rather like Michael's life story. Both his parents were obese; they tolerated his consumption of high fat and high calorie foods. Harry has tried and failed multiple diets during his life. $\mathrm{He}$ is genetically predisposed to high cholesterol levels; he has tried several statins but was discouraged by side effects, mostly muscle weakness, which was a problem for him as a construction worker. Both George and Harry need a left ventricular assist device ("LVAD") at a cost of $\$ 200,000$ to gain an extra two years of life. Both have the same insurance company and the same plan. George's LVAD will be paid for by his insurance but

$38 \quad$ It should be noted that there are now more than forty of these cancer drugs that are FDA approved and that have costs for a course of treatment in the range of $\$ 50,000-130,000$. None of these drugs cure an advanced cancer. Most of them can promise on average extra weeks to extra months of life. See Tito Fojo \& Christine Grady, How Much is Life Worth? Cetuximab, Non-Small Cell Lung Cancer, and the $\$ 440$ Billion Question, 101 J. NAT'L CANCER INST. 1044 (2009). 
that same company is requiring Harry to pay $\$ 100,000$ of the cost because he has been judged responsible for his heart disease. Harry is unable to pay that without leaving his future widow impoverished.

I argue that this outcome for Harry is unjust from a liberal egalitarian perspective. First, as argued earlier, there is considerable complexity and uncertainty associated with making a fair judgment that Harry is responsible for his late-stage heart failure but George is not. After all, George did a lot of weightlifting for exercise, which might have contributed to his having those heart attacks. But no one ever asked him about that, nor would that have made a difference with his insurance company. This sort of arbitrariness is alien to a liberal egalitarian conception of health care justice. If the LVAD were substantially less likely to yield the same level of quality-adjusted life years gained for Harry as opposed to George, that would be a justice-relevant consideration which would justify a differential allocation. But the best medical evidence would predict that they are equally likely to benefit. By way of contrast, the judgment of "irresponsibility" attached to Harry is much less soundly evidentially based, which is a second reason why this outcome is presumptively unjust.

Third, as I have argued elsewhere, just rationing protocols ought to be a product of fair processes of rational democratic deliberation. ${ }^{39}$ What we have to assume is that virtually everyone wants health care costs controlled, which is what creates the need for health care rationing. So we have to imagine ourselves as deliberators who are in basically good health and who are ignorant of what our future health care needs might be, including the degree to which we might be judged "responsible" for those needs. Deliberators would be urged to keep in mind the number of Americans beyond age fifty who are overweight or obese, the point being that that could be a future possible self for any of us. Still, I might be tempted to say that I am certain I will never be an alcoholic or drug abuser, and, consequently, I might be initially inclined to endorse a 
rationing protocol that would deny expensive life-prolonging care to individuals whose life-threatening health needs are related to alcoholism or drug abuse. But then I might be reminded through the deliberative process that $I$ have family or friends or co-workers who have struggled with these issues. I care about them and I am very familiar with their struggles and why they have had these struggles. Consequently, I would not want to see them die prematurely if there is medical care that can effectively address their medical problems.

Rationing decisions still need to be made. These rationing decisions must be ones that all could accept as "reasonable enough" and as "fair enough," given a fundamental commitment to equal concern and respect for all. Thus, we might all agree that if we were in late stage heart failure and in an advanced state of Alzheimer's disease (or comparable irreversible cognitive decline), we would deny our future possible selves an LVAD so that if, instead, I were in late stage heart failure for any reason at age sixty I would have access to an LVAD at social expense. The moral advantage of such a deliberative process is that it is public, transparent, rational (based on the best medical and scientific evidence available), and autonomously selfimposed (unlike judgments of personal "irresponsibility" made by self-authorized health saints and imposed on saint adjudicated health sinners). This is what Rawls refers to as "fair terms of cooperation." 40 If we could get beyond the vituperative political rhetoric that has characterized public conversation for the past decade we would easily collectively identify numerous rationing protocols such as the one above that would be fairer than any of the demands for punishing those identified as having made "irresponsible" health choices.

Finally, individuals should take more responsibility for their health. And our society should create a social and economic and educational environment wherein that can happen more easily. But I want to resist the claim that personal responsibility for health must be an integral part

40 See RAWLS, supra note 26, at Lecture Six, The Idea of Public Reason. 
of our conception of health care justice. The moral risk of such integration is that we would create two classes of patients: the deserving healthy (who would get a superior standard of care) and the undeserving unhealthy (who would get an inferior standard of care). Our conception of health care justice would then be desert-based rather than need-based. This is not an outcome that would be congruent with a liberal egalitarian conception of health care justice.

Consider the following example. James is 88 years old. $\mathrm{He}$ has been reasonably attentive to his health. He has also been blessed with an excellent genotype which has allowed him to age well. But he is now faced with some serious heart disease, mostly related to normal aging. Over the next several years he is treated with several somewhat expensive medications to ease the burden on his heart. $\mathrm{He}$ also needs coronary angioplasty to keep open a couple coronary arteries that have narrowed. Altogether he has been the beneficiary of about $\$ 110,000$ worth of health care over the past four years. But he now has end-stage heart failure, just like George and Harry. But the LVAD will not do him enough good. He needs a totally implantable artificial heart ("TIAH") at a cost of $\$ 300,000$. Such a device promises on average five extra years of life expectancy. If our conception of health care justice is desert-based, then we would have no basis for denying his request, even though his longevity is likely as much a product of his genotype and his social environment ("brute luck") as his attentiveness to his personal health ("option luck").41 Let us add to this scenario a variant of Harry. Harry is sixty years old. His heart failure is such that an LVAD will not be good enough to prolong his life. He too needs a TIAH. Because

41 Various writers have called attention to the role of social environment in support of personal responsibility for health. Or, put another way, there will be more "irresponsibility" for health among social groups that are the objects of various forms of social discrimination as well as among individuals in the lower reaches of the economic spectrum in our society. See, e.g., Susan Hurley, The Public Ecology of Responsibility, in RESPONSIBILITY AND DISTRIBUTIVE JUSTICE 187-215 (Carl Knight \& Zofia Stemplowska eds., 2011); see also Daniels, supra note 27. 
he is younger, however, his predicted life expectancy with the TIAH would be an additional ten to fifteen years. Though Harry is insured, he would be expected to cover $\$ 150,000$ of the cost of the TIAH. He cannot afford that. There is something fundamentally unjust in this state of affairs. At the very least Harry is being denied the opportunity to achieve a normal life expectancy when the medical technology is available that would make that possible. At the same time James is being "rewarded" with a substantially enhanced life expectancy, far beyond a normal life expectancy, and this is a social expense. That is, we are all paying for that enhancement. Or perhaps we could say that the resources saved by allowing Harry to die are being transferred to James so that he might reach age ninety-seven.

We can identify the justice concerns in yet another way. Cancer is largely a disease of older individuals. We can imagine James with his artificial heart afflicted with a pancreatic cancer at age ninety-four. Again, this will just be a matter of brute (bad) luck. So if we adopt a desert-based luck egalitarian perspective rather than a liberal egalitarian perspective, then we would again be obligated as a matter of justice to provide James with a $\$ 100,000$ cancer drug that might yield only three extra months of life for James (above what he would get without the drug). From a cost-effectiveness perspective the cost of this drug would be $\$ 400,000$ per Quality-Adjusted Life Year ("QALY"). The point is that James-like individuals who have been very fortunate health-wise would have a moral right (just claim) to unlimited marginally beneficial and extraordinarily costly health care while Harry-like individuals would be denied very cost-effective health care that was necessary for them to achieve a normal life expectancy. To be precise, if Harry gained just ten extra years of life with the TIAH, the cost per QALY would be $\$ 30,000$.

We return to our rational democratic deliberation. If we were relatively young and in good health, and if we could see our future possible selves as Harry-like or James-like individuals (the same being true for others about whom we cared deeply), and if we sought fair terms of cooperation 
with regard to the allocation of limited health care resources, and if we were committed to equal concern and respect for all, then would we see a conception of justice that yielded the James-like results described above as being "just enough"? It is difficult to imagine an affirmative answer emerging from this deliberative process, much less the reasons that would justify such an outcome. In the final analysis trying to control health care costs by denying equal access to individuals whose health care needs are judged a product of "irresponsible" behavior will be illiberal, unjust, uncaring and threatening to the values central to the practice of medicine. 
